\title{
Modern Postpartum Contraception: The Experience of Nabil Choucair Health Center, Dakar (Senegal)
}

\author{
Babacar Biaye*, Khadidiatou Ndour, Omar Gassama, Youssoupha Toure, Mor Cissé, \\ Abdou Ndiaye, Abdoul Aziz Diouf, Mamour Gueye, Alassane Diouf, Jean Charles Moreau \\ Gynecological and Obstetric Clinic of Aristide Hospital Le Dantec of Dakar, Dakar, Senegal \\ Email: *drbabacarbiaye@yahoo.fr
}

How to cite this paper: Biaye, B., Ndour, K. Gassama, O., Toure, Y., Cissé, M., Ndiaye, A., Diouf, A.A., Gueye, M., Diouf, A. and Moreau, J.C. (2020) Modern Postpartum Contraception: The Experience of Nabil Choucair Health Center, Dakar (Senegal). Open Journal of Obstetrics and Gynecology, 10, 930-945.

https://doi.org/10.4236/ojog.2020.1070088

Received: May 8, 2020

Accepted: July 21, 2020

Published: July 24, 2020

Copyright () 2020 by author(s) and Scientific Research Publishing Inc. This work is licensed under the Creative Commons Attribution International License (CC BY 4.0).

http://creativecommons.org/licenses/by/4.0/

\section{(c) (i) Open Access}

\begin{abstract}
Introduction: In Senegal, according to the 2017 Demographic Health Survey, about $22 \%$ of married women have an unmet need for family planning. Globally, $61 \%$ of women do not have access to postpartum family planning. Material and Method: This is a prospective, descriptive and analytical study from March 05, 2017 to January 31, 2018. The interrogation was done in the hospital ward with filling in the data collection form. The data collected was first coded and then entered, using the sphinx software. The data analysis was done with Epi info version 7 software and included a descriptive and analytical component. Results: The average age of the patients was 26 years with extremes of 15 and 48 years. Average gestation was 2.3 with extremes of 1 and 8 pregnancies. More than half of the women (64.7\%) had delivered by caesarean in an emergency setting. More than half of the women (66.7\%) had chosen the hormonal contraceptive method within 48 hours of delivery and the implant was the type of contraceptive prescribed in almost half of the cases (49.3\%). Conclusion: Integrating postpartum family planning into programs will ultimately help to dramatically decrease high-risk pregnancies, decrease the unmet need for family planning (FP), and improve the health and survival of mothers and children.
\end{abstract}

\section{Keywords}

Contraception, Postpartum, Mother and Child Health

\section{Introduction}

Family planning (FP) is a major pillar of reproductive health care that can be provided before pregnancy, immediately after delivery, and during the first year 
after delivery. It is important throughout the reproductive life of a couple or an individual, and is a means of achieving the desired number of children and determining the spacing between births. Postpartum family planning (PFPP) is of particular interest for the prevention of close and unwanted pregnancies during the first 12 months after childbirth. In typical maternal and newborn health programs, the postpartum period is defined as six weeks after birth, but in the context of PPFP, this period refers to the first year after birth. Thus postpartum contraception refers to the use of agents, devices, methods and procedures to reduce the conception of a conception or to avoid it. It only refers to temporary and reversible methods [1].

Indeed, according to a consultation initiated by the World Health Organization (WHO), after a live birth, the recommended interval before planning a new pregnancy is at least 24 months, in order to reduce the risks related to maternal, perinatal and child health [2]. Despite this fact, $61 \%$ of women do not use effective contraception methods within 24 months after birthing to avoid an unintended pregnancy [1] [2].

It is in this context that we conducted this study whose objectives were:

- To assess the nature of contraceptive demand in the postpartum at the maternity of the Nabil Chaoucair Health Center;

- To look for factors likely to influence the acceptability of postpartum contraception.

\section{Methodology}

\subsection{Type and Period of Study}

We conducted a looking-forward study, through a semi-structured survey form with open or closed questions, single-choice or multiple-choice questions addressed to patients. The study period ranged from 05 March 2017 to 31 January 2018.

\subsection{Study Population}

The included patients were selected among those who gave birth in the hospital from March 5, 2017 to January 31, 2018, within 48 hours of delivery. The survey period was within the 48 hours after delivery. The medical records were selected and the inclusion criteria involved:

$\checkmark$ Being hospitalized in the maternity ward;

$\checkmark$ Confirmed consent to participate in the study.

Patients who refused to be interviewed were not included in the study.

\section{Data Collection}

\subsection{Sampling}

Our population consisted of 150 patients who gave birth at Nabil Choucair Health Center during our study period. 


\subsection{Interrogation}

The interview was conducted in the hospitalisation room with the data collection form being filled out.

\subsection{Anamnesis Time Length}

The average duration of the interview was twenty (20) minutes for each patient.

\subsection{Items Studied}

The data collection form included the following items:

- Socio-demographic characteristics (age, marital status, occupation, gender, etc.);

- Data from the last pregnancy and childbirth:

- Antenatal care (profile of the provider who performed the antenatal care, completeness of the follow-up, pregnancy assessment, ultrasound, tetanus prevention, pathology during pregnancy);

- Term of pregnancy;

- Delivery (route of delivery, complications);

- Newborn (birth status, weight, sex ratio, breastfeeding);

- Contraception:

- Contraceptive history of respondent new-mothers;

- Time of information on postpartum contraception;

- Contraceptive method prescribed;

- Information on adverse effects;

- Descriptive pane:

In the descriptive part, the qualitative variables were described in terms of number and in percentage.

The quantitative variables were described on average with, standard deviation, extremes, and the median.

\subsection{Data Processing}

The data collected was first coded and then entered using the sphinx software. The data analysis was done with the Epi info version 7 software and featured two parts:

\section{- Descriptive section}

In the descriptive section, the qualitative variables were reported by number of employees, percentage.

Quantitative variables were described in mean, standard deviation, extremes, median.

\section{- Analytical section}

It consisted of a bivariate analysis by comparing postpartum contraceptive agreement with other variables. For statistical tests, we used the Chi-square test for the percentage comparison, the student test or ANOVA for mean comparison. The difference was statistically significant when the p value was strictly below 0.05 . 
ORs and confidence intervals [95\% CI] were used to determine the strength of the link.

\section{Results}

\subsection{Descriptive Results}

\subsubsection{Socio-Demographic Characteritics}

\section{- Age}

The mean age of the patients was 26 years with extremes range from 15 to 48 years as reported in Figure 1.

- Marital status

More than 3 of 4 patients were monogamous as shown in Figure 2.

\section{- Occupation}

Nearly 4 out of 5 patients (78\%) had no professional occupation, while students accounted for $8 \%$ as shown in Table 1.

- Level of instruction

Nearly half of the patients were uneducated (44\%) while only $5.3 \%$ had a university level (Figure 3).

- Monthly income

More than 4 out of 5 patients had a monthly income of less than 50,000 FCFA (78.2 euros) (Figure 4).

\subsubsection{Pregnancy and Delivery}

- Obstetrical data

o Gestity

The mean gestation was 2.3 with extremes range from 1 to 8 pregnancies. More than one-third of the patients (39.3\%) were in their first pregnancy (Table 2).

o Parity

The average parity was 2.2 with extremes range from 1 to 7 births. Primiparous women accounted for $42 \%$ (Table 3 ).

\section{o Number of children}

The average number of living children was 2 children with extremes range from 0 to 7 children.

More than half of the patients (54.7\%) had 2 or more children.

- Antenatal monitoring

o Pregnancy type

Pregnancy was spontaneous in more than half of the patients (63\%) as shown in Table 4.

o Personnel who followed the pregnancy

Almost all women (91.3\%) were monitored by midwives.

The mean number of ANCs performed was 3.5 with extremes range from 0 to 5 ANCs. Nearly one-third of the patients (29\%) didn't undergo ANC.

In addition, $69.4 \%$ of the women had undergone at least 4 ANCs, as shown in Figure 5. 


\section{- Pregnancy outcome}

\section{o Delivery route}

More than half of the women (64.7\%) had an emergency Ceasarean ection (Figure 6).

\section{o Term of the pregnancy}

Almost all patients (88\%) had full-term deliveries (Table 5).

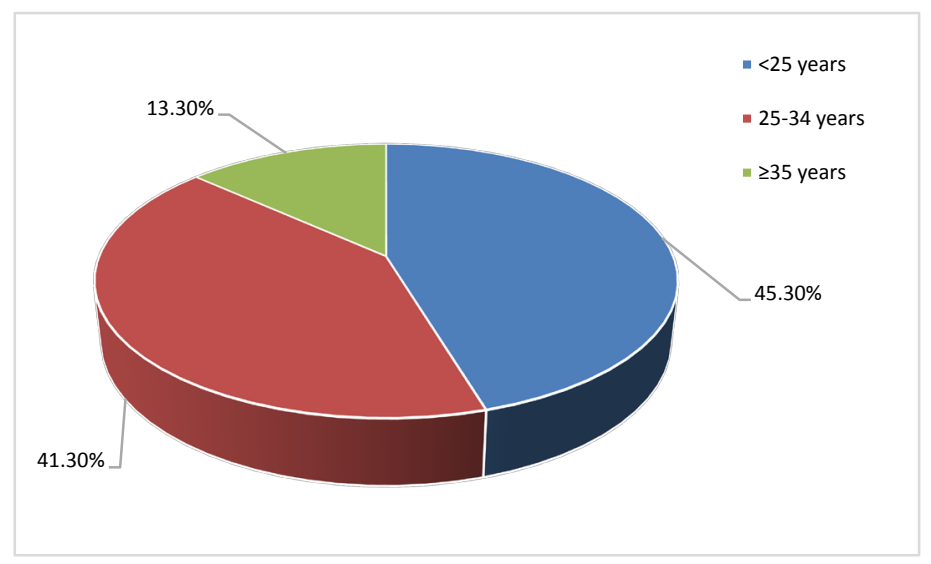

Figure 1. Distribution of patients by age group $(\mathrm{N}=150)$.

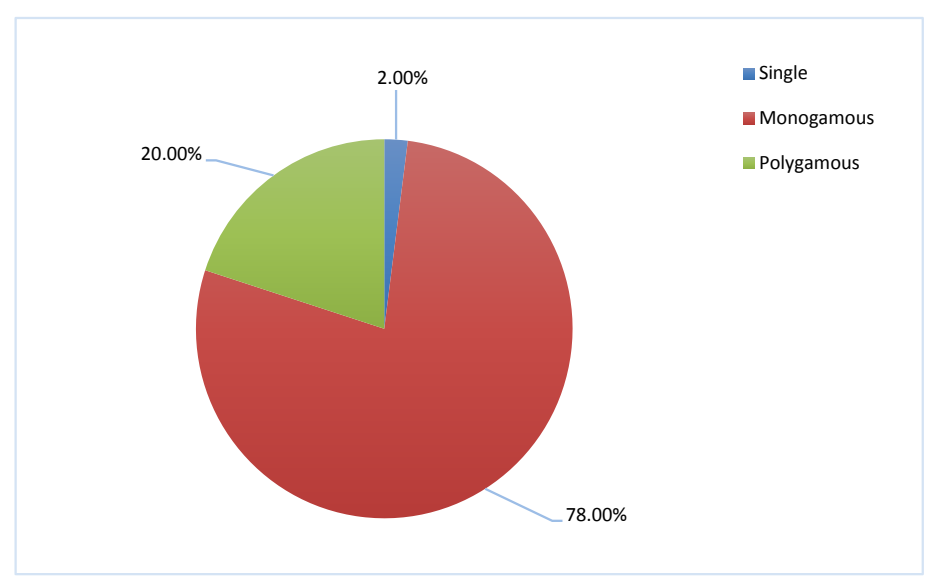

Figure 2. Distribution of patients according to marital status $(\mathrm{N}=150)$.

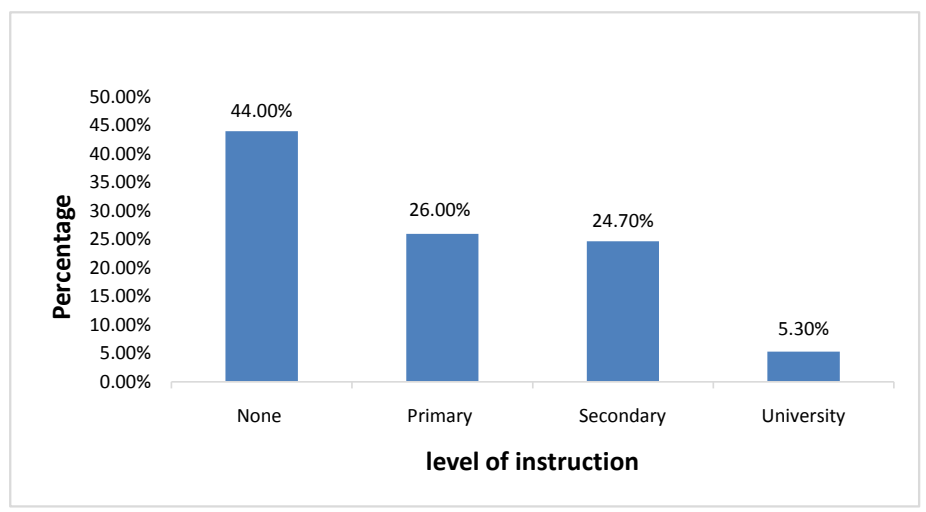

Figure 3. Distribution of patients by level of education $(\mathrm{N}=150)$. 


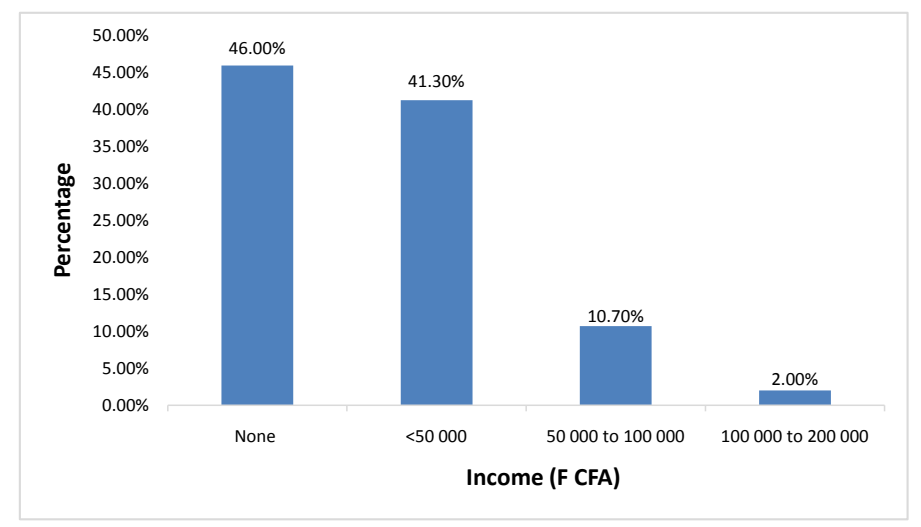

Figure 4. Distribution of patients according to the monthly income $(\mathrm{N}=150)$.

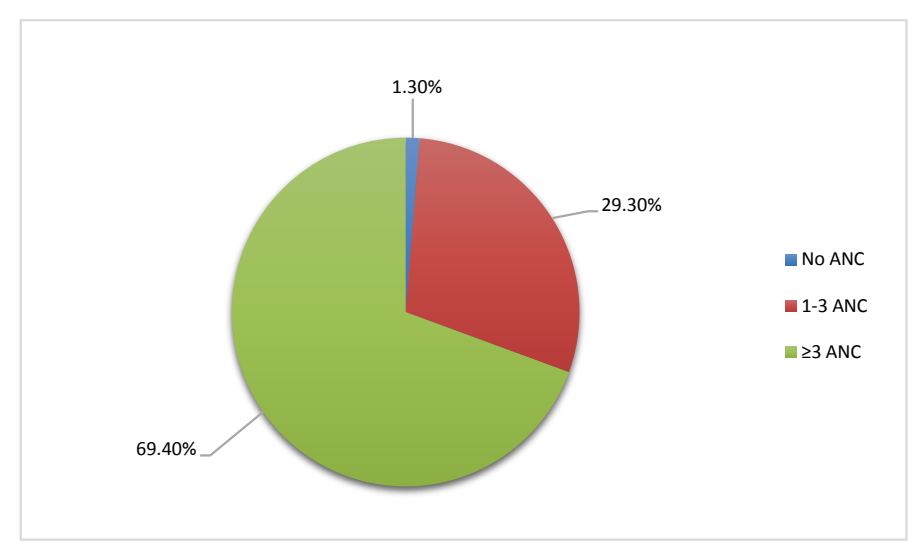

Figure 5. Patient distribution according to the number of ANC performed $(\mathrm{N}=150)$.

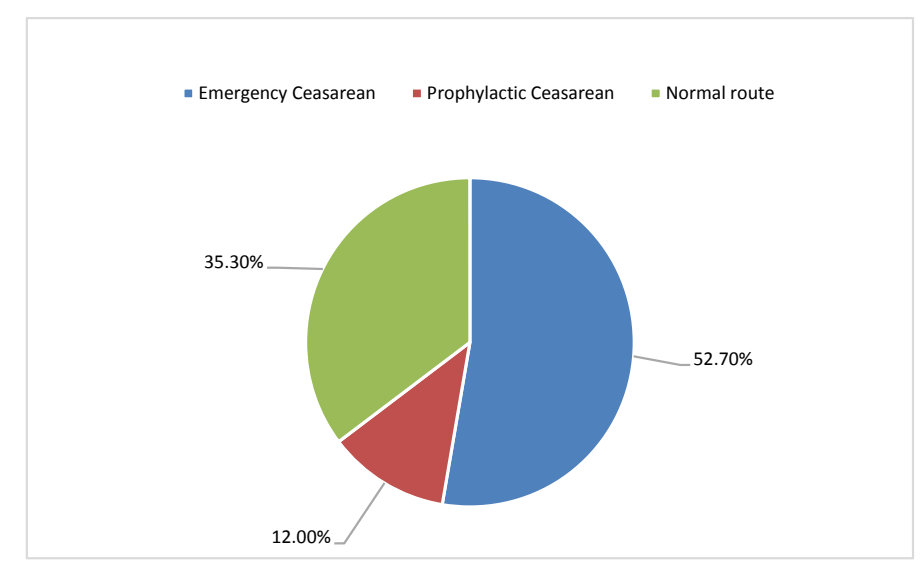

Figure 6. Patients distribution according to the route of delivery $(\mathrm{N}=150)$.

Table 1. Patient distribution according to their occupation.

\begin{tabular}{ccc}
\hline Profession & Frequency & Percentage \\
\hline Without occupation & 108 & 78 \\
Trader & 22 & 14.7 \\
Pupil/student & 12 & 8 \\
minor occupation & 7 & 5.4 \\
Total & 150 & 100 \\
\hline
\end{tabular}


Table 2. Patients distribution according to gestity.

\begin{tabular}{ccc}
\hline Gestity & Frequency & Percentage \\
\hline Primigravida & 59 & 39.3 \\
Paucigravida & 42 & 28 \\
Multigravida & 22 & 14.7 \\
Grand multigravida & 27 & 18 \\
Total & 150 & 100 \\
\hline
\end{tabular}

Table 3. Patient distribution according to the parity.

\begin{tabular}{ccc}
\hline Parity & Frequency & Percentage \\
\hline Primiparous & 63 & 42 \\
Pauciparous & 47 & 31.3 \\
Multiparous & 16 & 10.7 \\
Grand multiparous & 24 & 16 \\
Total & 150 & 100 \\
\hline
\end{tabular}

Table 4. Patients distribution according to the type of pregnancy.

\begin{tabular}{ccc}
\hline Pregnancy & Frequency & Percentage \\
\hline Spontaneous & 96 & 70 \\
Planned & 40 & 26.7 \\
Unplanned & 14 & 9.3 \\
Induced & 0 & 0 \\
Total & 150 & 100 \\
\hline
\end{tabular}

Table 5. Patient distribution according to the term of the pregnancy.

\begin{tabular}{ccc}
\hline Term of the pregnancy & Frequency & Percentage \\
\hline Term & 132 & 88 \\
Premature & 3 & 2 \\
Post term & 5 & 10 \\
Total & 150 & 100 \\
\hline
\end{tabular}

\section{Newborn}

\section{o Weight}

The average weight of newborns was 3137 grams (Table 6). More than half of the newborns (54\%) were male.

\section{o Newborn outcome}

Almost all newborns (97.3\%) were alive.

\section{o Breastfeeding}

Exclusive breastfeeding was performed in more than 4 out of 5 patients $(85.6 \%)$ (Table 7). 
Table 6. Patient distribution according to the newborn's weight.

\begin{tabular}{ccc}
\hline Weight & Frequency & Percentage \\
\hline$<2500$ grams & 10 & 6.7 \\
$2500-3500$ grams & 112 & 74.7 \\
$\geq 3500$ grams & 28 & 18.6 \\
Total & 150 & 100 \\
\hline
\end{tabular}

Table 7. Patient distribution according to the feeding method.

\begin{tabular}{ccc}
\hline Conducted breastfeeding & Frequency & Percentage \\
\hline Maternal & 128 & 85.6 \\
Mixed & 17 & 11.6 \\
Artificial & 4 & 2.8 \\
Total & 150 & 100 \\
\hline
\end{tabular}

\subsubsection{Contraception}

\section{- Contraception history}

More than half of the patients $(55.3 \%)$ were not under contraception as reported in Table 8.

- Spouse's or another person's agreement for contraceptive choice Overall 105 patients (70\%) required the consent of a spouse or another person.

\section{- Postpartum Contraception Counseling}

More than 4 out of 5 patients were discussed about contraception during the immediate post-partum period. Only 10 patients were discussed about contraception during the antenatal visit (Table 9).

- Chosen contraceptive method

More than half of the women $(66.7 \%)$ had chosen the hormonal contraceptive method within the 48 hours after giving birth (Figure 7).

\section{- Type of contraception prescribed}

The implant was the type of contraceptive prescribed in nearly half of the cases (49.3\%) (Table 10).

\section{- Information on adverse effects}

Almost all patients $(90.7 \%)$ had been informed about precautions related to side effects.

\section{- Availability of contraceptive information sheet}

More than half of the patients had received a contraceptive information sheet (Table 11).

\subsection{Analytical Results}

\subsubsection{Post Partum Contraception According to Socio-Demographic Characteristics}

According to socio-demographic characteristics, postpartum contraception agreement was higher among women aged 35 or older, polygamous, those who had a 
professional occupation with a monthly income of more than 50,000. However, the difference was not statistically significant with a p value $=0.408$.

There was also a statistically significant difference lloking at the education level. Women with a high school education or higher were twice as likely to accept the postpartum contraceptive method. Table 12 illustrates the results.

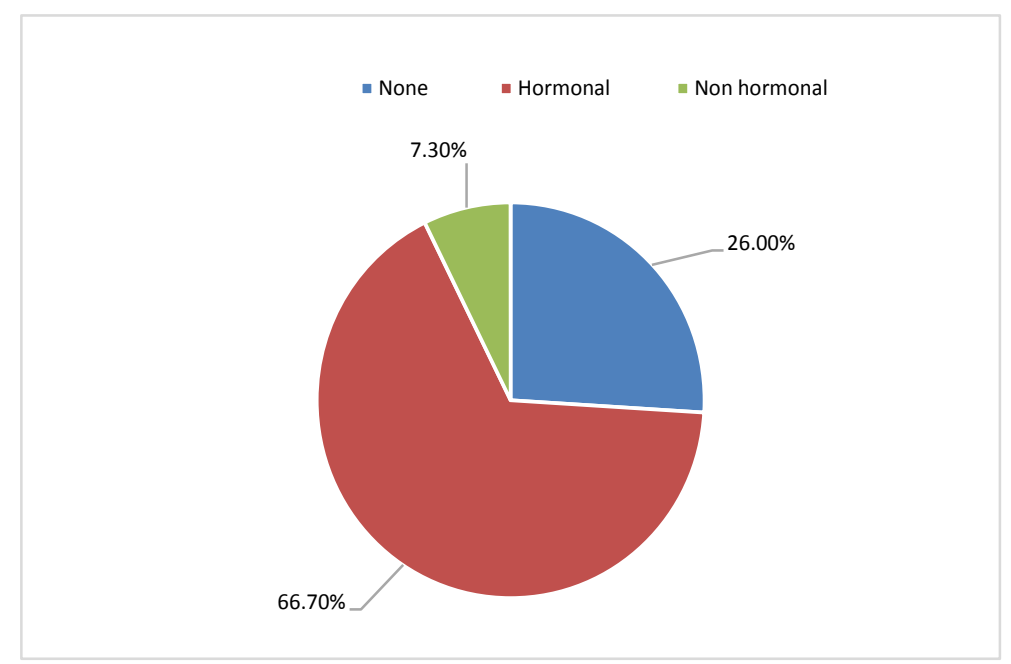

Figure 7. Patient distribution according to the chosen contraceptive method $(\mathrm{N}=150)$.

Table 8. Patient distribution according to contraception history.

\begin{tabular}{ccc}
\hline History of contraception & Frequency & Percentage \\
\hline None & 83 & 55.3 \\
Implant & 24 & 16 \\
Pill & 18 & 12 \\
Depo-provera & 14 & 9.3 \\
Intra-uterine device & 10 & 6.7 \\
Others & 1 & 0.7 \\
Total & 150 & 100 \\
\hline
\end{tabular}

Table 9. Patient distribution according to the time of contraception counseling.

\begin{tabular}{ccc}
\hline Time of contraception counseling & Frequency & Percentage \\
\hline Post partum & 121 & 82.7 \\
Delivery room & 14 & 9.3 \\
Antenal care & 10 & 6.7 \\
Delivery preparation & 3 & 2 \\
postnatal care & 2 & 1.3 \\
Total & 150 & 100
\end{tabular}


Table 10. Patient distribution according to the prescribed contraception.

\begin{tabular}{ccc}
\hline Type of contraception prescribed & Frequency & Percentage \\
\hline Implants & 74 & 49.3 \\
Dépoprovera & 20 & 13.3 \\
Intra-uterine device & 11 & 7.3 \\
Pill & 6 & 4 \\
Advice only & 21 & 14 \\
None & 18 & 12 \\
Total & 150 & 100 \\
\hline
\end{tabular}

Table 11. Contraceptive information sheet availability.

\begin{tabular}{ccc}
\hline Reasons & Frequency & Percentage \\
\hline Yes & 95 & 63 \\
without opinion & 33 & 22 \\
No & 22 & 15 \\
Total & 150 & 100 \\
\hline
\end{tabular}

Table 12. Relationship between the use of contraceptive method and socio-demographic characteristics.

\begin{tabular}{|c|c|c|c|c|c|c|c|}
\hline \multirow{3}{*}{$\begin{array}{c}\text { Socio-demographic } \\
\text { characteristics }\end{array}$} & \multicolumn{4}{|c|}{ Contraception acceptance } & \multirow{3}{*}{ Total } & \multirow{3}{*}{$\mathrm{p}$ value } & \multirow{3}{*}{$\begin{array}{c}\text { Or } \\
{[\mathrm{IC} \text { à } 95 \%]}\end{array}$} \\
\hline & \multicolumn{2}{|c|}{ Yes } & \multicolumn{2}{|c|}{ No } & & & \\
\hline & $\mathrm{N}$ & $\%$ & $\mathrm{~N}$ & $\%$ & & & \\
\hline \multicolumn{8}{|l|}{ Age group } \\
\hline$<25$ year & 50 & 73.5 & 18 & 26.5 & 68 & & \\
\hline 25 - 34 years & 44 & 71.0 & 18 & 29.0 & 62 & 0.458 & \\
\hline$\geq 35$ years & 17 & 85.0 & 3 & 15.0 & 20 & & \\
\hline \multicolumn{8}{|l|}{ Marital status } \\
\hline Single & 2 & 66.7 & 1 & 33.3 & 3 & & \\
\hline Monogamous & 76 & 73.5 & 31 & 26.5 & 117 & 0.9 & \\
\hline Polygamous & 23 & 76.7 & 7 & 23.3 & 30 & & \\
\hline \multicolumn{8}{|l|}{ Professional occupation } \\
\hline Yes & 22 & 73.3 & 8 & 26.7 & 30 & 0.925 & \\
\hline No & 89 & 74.2 & 31 & 25.8 & 120 & & \\
\hline \multicolumn{8}{|l|}{ Instruction } \\
\hline Primary & 72 & 69.2 & 32 & 30.8 & 104 & 0.045 & 1 \\
\hline High school or more & 39 & 84.8 & 7 & 15.2 & 46 & & $2.5[1.1-6.1]$ \\
\hline \multicolumn{8}{|l|}{ Monthly income } \\
\hline$\leq 50,000$ & 94 & 71.8 & 37 & 28.2 & 131 & 0.099 & \\
\hline$>50,000$ & 17 & 89.5 & 2 & 10.5 & 19 & & \\
\hline
\end{tabular}




\subsubsection{Post-Partum Contraception Based on Obstetrical History}

Postpartum contraception agreement was almost similar depending on the obstetrical history. Table 13 illustrates the results.

\subsubsection{Post-Partum Contraception According to Delivery}

The percentage of postpartum contraception acceptance was almost similar according to the delivery-related data. Table 14 illustrates the results.

\subsubsection{Post-Partum Contraception Based on Newborn Data}

The percentage of post-partum contraception acceptance was almost similar according to the data on fetal outcome (Table 15).

\subsubsection{Post-Partum Contraception According to Information Received on Contraception}

The distribution of postpartum contraceptive agreement varied according to the information received on contraception. Women who were on contraceptive methods, those who did not require the consent of a spouse or an another person to choose a method, and those who received an information form were 2.6, 7.3 and 4.4 times more likely to accept postpartum contraception. Table 16 illustrates the results.

Table 13. Relationship between the use of contraceptive method and obstetrical history.

\begin{tabular}{|c|c|c|c|c|c|c|}
\hline \multirow{3}{*}{ Obstetrical history } & \multicolumn{4}{|c|}{ Contraception acceptance } & \multirow{3}{*}{ Total } & \multirow{3}{*}{$\mathrm{p}$ value } \\
\hline & \multicolumn{2}{|c|}{ Yes } & \multicolumn{2}{|c|}{ No } & & \\
\hline & $\mathrm{N}$ & $\%$ & $\mathrm{~N}$ & $\%$ & & \\
\hline \multicolumn{7}{|l|}{ Gestité } \\
\hline Primigravida & 42 & 71.2 & 17 & 28.8 & 59 & \\
\hline Paucigravida & 31 & 73.8 & 11 & 26.2 & 42 & 0.904 \\
\hline Multigravida & 17 & 77.3 & 5 & 22.7 & 22 & \\
\hline Grand multigravida & 21 & 77.8 & 6 & 22.2 & 27 & \\
\hline \multicolumn{7}{|l|}{ Parity } \\
\hline Primiparous & 45 & 71.4 & 18 & 28.6 & 63 & \\
\hline Pauciparous & 33 & 70.2 & 14 & 29.8 & 47 & 0.49 \\
\hline Multiparous & 14 & 87.5 & 2 & 12.5 & 16 & \\
\hline High multiparous & 19 & 79.2 & 5 & 20.8 & 24 & \\
\hline \multicolumn{7}{|l|}{ Number of children } \\
\hline$\leq 1$ child & 47 & 69.1 & 21 & 30.9 & 68 & 0.214 \\
\hline$\geq 2$ children & 64 & 78 & 18 & 21.9 & 82 & \\
\hline \multicolumn{7}{|l|}{ Forseen pregnancy } \\
\hline Planned & 28 & 70 & 12 & 30.0 & 40 & 0.5 \\
\hline Unplanned & 83 & 75.4 & 27 & 24.5 & 110 & \\
\hline
\end{tabular}


Table 14. Crossover between contraceptive method and delivery method.

\begin{tabular}{|c|c|c|c|c|c|c|}
\hline \multirow{3}{*}{ delivery } & \multicolumn{4}{|c|}{ Contraception agreement } & \multirow{3}{*}{ Total } & \multirow{3}{*}{$\mathrm{p}$ value } \\
\hline & \multicolumn{2}{|c|}{ Yes } & \multicolumn{2}{|c|}{ No } & & \\
\hline & $\mathrm{N}$ & $\%$ & $\mathrm{~N}$ & $\%$ & & \\
\hline Route of delivery & & & & & & 0.634 \\
\hline vaginal & 38 & 71.7 & 15 & 28.3 & 53 & \\
\hline C-Section & 73 & 75.3 & 24 & 24.7 & 97 & \\
\hline Full-term pregnancy & & & & & & 0.335 \\
\hline Yes & 96 & 72.7 & 36 & 27.3 & 132 & \\
\hline No & 15 & 83.3 & 3 & 16.7 & 18 & \\
\hline Complications & & & & & & 0.31 \\
\hline Yes & 55 & 70.5 & 23 & 29.5 & 78 & \\
\hline No & 56 & 77.8 & 16 & 22.2 & 72 & \\
\hline EBF & & & & & & 0.164 \\
\hline Yes & 89 & 71.2 & 36 & 28.8 & 125 & \\
\hline No & 18 & 85.7 & 3 & 14.3 & 21 & \\
\hline
\end{tabular}

Table 15. Distribution of Postpartum Contraceptive acceptance according to newborn-related data.

\begin{tabular}{|c|c|c|c|c|c|c|}
\hline \multirow{3}{*}{ Newborn } & \multicolumn{4}{|c|}{ Contraception agreement } & \multirow{3}{*}{ Total } & \multirow{3}{*}{$\mathrm{p}$ value } \\
\hline & \multicolumn{2}{|c|}{ Yes } & \multicolumn{2}{|c|}{ No } & & \\
\hline & $\mathrm{N}$ & $\%$ & $\mathrm{~N}$ & $\%$ & & \\
\hline Outcome & & & & & & 0.229 \\
\hline Alive & 107 & 73.3 & 39 & 26.7 & 146 & \\
\hline Stillbirth & 4 & 100.0 & 0 & 0.0 & 4 & \\
\hline
\end{tabular}

Table 16. Distribution of postpartum contraception agreement according to contraceptive information.

\begin{tabular}{|c|c|c|c|c|c|c|c|}
\hline \multirow{3}{*}{$\begin{array}{l}\text { Information about post } \\
\text { partum contraception }\end{array}$} & \multicolumn{4}{|c|}{ Contraception agreement } & \multirow{3}{*}{ Total } & \multirow{3}{*}{$\mathrm{p}$ value } & \multirow{3}{*}{ OR [IC à 95\% } \\
\hline & \multicolumn{2}{|c|}{ Yes } & \multicolumn{2}{|c|}{ No } & & & \\
\hline & $\mathrm{N}$ & $\%$ & $\mathrm{~N}$ & $\%$ & & & \\
\hline Contraception history & & & & & & 0.016 & \\
\hline Yes & 56 & 83.6 & 11 & 16.4 & 67 & & $2.6[1.2-5.7]$ \\
\hline No & 55 & 66.3 & 28 & 33.7 & 83 & & 1 \\
\hline $\begin{array}{l}\text { Need of the spouse's } \\
\text { agreement for the choice }\end{array}$ & & & & & & 0.001 & \\
\hline Yes & 69 & 65.7 & 36 & 34.3 & 105 & & 1 \\
\hline No & 42 & 93.3 & 3 & 6.7 & 45 & & $7.3[2.1-25.2]$ \\
\hline
\end{tabular}


Continued

\begin{tabular}{cccccccc}
\hline $\begin{array}{c}\text { Time of information } \\
\text { about contraception }\end{array}$ & & & & & & 0.801 \\
Before delivery & 10 & 76.9 & 3 & 23.1 & 13 & \\
During delivery & 101 & 73.7 & 36 & 26.8 & 137 & \\
$\begin{array}{c}\text { Information on } \\
\text { adverse effects }\end{array}$ & & & & & & 0.091 & \\
Yes & 98 & 72.1 & 38 & 27.9 & 136 & \\
No & 13 & 92.9 & 1 & 7.1 & 14 & & \\
Information form & & & & & & 0.012 & \\
Yes & 30 & 90.9 & 3 & 9.1 & 33 & & \\
No & 81 & 69.2 & 36 & 30.7 & 117 & & $4.3-15.5]$ \\
\hline
\end{tabular}

\section{Discussion}

\subsection{Socio-Demographic Characteristics and Their Influences on Family Planning}

\subsubsection{Age}

Distribution by age group outlines that they were mostly young women, most of whom were under 25 years of age (46\%), which is higher than the $40.5 \%$ found in the general population [3] [4]. The difference could be explained by the fact that our study was conducted mainly in urban areas.

\subsubsection{Marital Status}

Almost all of the patients included in our study were married. These women, most of whom were in a couple, therefore had sexual activity that could be resumed quickly, which would justify more frequent use of a contraceptive method.

\subsubsection{Educational Level}

In our sample, the educational level of the women interviewed is relatively low. Nearly half of the women had no formal education at all and one third had completed primary school. Only $5.3 \%$ of the women interviewed had attended university.

This proportion of patients with a low level of education suggests a misunderstanding of the information conveyed. Therefore, there was a statically significant difference between the level of education and contraceptive method agreement.

\subsubsection{Parity}

In Senegal over the past 25 years, the total fertility rate has declined slowly but steadily, from 6.4 children per woman in 1986 to 6.0 in 1992, 5.7 in 1997, 5.3 in 2005, 5.0 in 2010-11 and 4.6 in 2017 [5.6]. The use of contraceptive method increases progressively with parity, from $3 \%$ among nulliparous women to $23 \%$ among women with 1 to 2 children and $27 \%$ among those with 5 or more children [3]. 
In our sample, fertility was estimated at 2 children per woman, which is lower than in the general population, probably for two reasons: our study was restricted to the postpartum period and was conducted in urban areas where fertility is lower. The majority of these women were primiparous or pauciparous, followed by large multiparous, and there was no correlation between parity and choice of contraceptive method.

\subsubsection{Route of Delivery}

In Senegal during the period range from 2012 to 2017 the percentage of births by Caesarean section has slightly changed between $4 \%$ and 5\% [5] [6]. In our study 64.7\% underwent a Caesarean section. This could be explained by the size of our sample and the fact that most pregnancies were affected by complications. The use contraception was similar regardless of the route of delivery.

\subsubsection{Breastfeeding}

In our survey, most of the women (85.6\%) chose to breastfeed their child. This rate is lower than that found in the overall Senegalese population (99\%) [7]. However, in developed countries, the breastfeeding rate has decreased considerably [8] [9] [10].

This could be justified by the fact that the study was carried out in urban areas; the physionomy of occupations being different between the city and the countryside. For example, the great diversity of urban jobs contrast with a concentration of rural populations in the agricultural sector.

\subsection{Contraceptive Methods in the Postpartum Period}

Our results outline that the most commonly used type of contraception is the implant (49.3\%) followed by depoprovera (13.3\%). The intra uterine device and the pill are used in $7.3 \%$ and $6.4 \%$ of the cases respectively. The contraceptive method chosen in our context differs from that found in most studies where the progestin-only pills are in the frontline. Thus, Froger found the pill usage in 54.2\% of the cases, followed by the IUD (13.5\%) and the implant (9.4\%) [10], while in the Genton study, $43.3 \%$ of women were on the progestogen-only pills and $10 \%$ of women benefited from progestogen-based contraception with a subcutaneous implant placed in the ward before returning home [11].

In the French study reported by Blangis, the majority of women had chosen oral microprogestogens accounting for 63.5\% [12] and 65.1\% in the Morgane sample [13].

\subsection{Information on Side Effects}

One patient out of 10 felt that they had not been informed about the side effects of certain contraceptive methods, even though the occurrence of these adverse effects is the main cause of contraceptive discontinuation.

In the literature, Stein shows that service delivery centers in Senegal were not doing enough to meet the specific needs of breastfeeding women who wanted planning services [7]. 


\subsection{Limits of the Study}

Our study involved a not too large cohort because it only included data from a health center. The duration of the study did not allow monitoring of long-term side effects of contraceptives.

\section{Conclusion}

The postpartum period, especially immediately after childbirth, is a period during which couples typically have multiple contacts with the health care system. Providing contraception during this period is cost-effective and efficient because it does not require significant increases in personnel, supervision, or infrastructure. In addition, for the many women who rarely use the health care system, family planning (FP) provided in the period immediately after childbirth does not require a costly and burdensome return to the facility, thereby increasing the opportunities to reach couples and increase their awareness of FP. Integrating postpartum family planning into programmes helps to expand services for women in the first year after delivery, and to increase the use of FP among women and their partners during this first year, and will ultimately lead to a significant reduction in high-risk pregnancies, a decrease in unmet need for FP, and improved maternal and child health and survival.

\section{Conflicts of Interest}

The authors declare no conflicts of interest regarding the publication of this paper.

\section{References}

[1] Department of Reproductive Health World Health Organization (2005) Admissibility Criteria for the Adoption and Continued Use of Contraceptive Methods. 3rd Edition, WHO Press Geneva, Switzerland.

[2] WHO Library (2014) Programming Strategies for Postpartum Family Planning. World Health Organization, Geneva. http://apps.who.int/iris/bitstream/10665/99116/1/9789242506495_eng.pdf

[3] ANAES Breastfeeding (2002) Implementation and Continuation in the First 6 Months of the Child's Life. http://www.has-sante.fr/portail/upload/docs/application/pdf/Allaitement_rap.pdf

[4] Blangis, F., Lopes, P., Branger, B., et al. (2013) The Postnatal Contraception: Upon 600 Patients of Whom 129 Were Postnatal Controlled. Obstetrics and Fertility Gynecology, 41, 499-504. https://doi.org/10.1016/j.gyobfe.2013.07.017

[5] National Agency for Health Accreditation and Assessment (2004) Strategies for Choosing Contraceptive Methods in Women. Geneva, Switzerland, 47.

[6] National Agency for Statistics and Demography, Senegal (2017) Continuous Demographic and Health Survey (EDS-Continues). Official Journal of the Republic of Senegal, Dakar, Senegal, 17-60.

[7] Stein, K., Measham, D. and Winikoff, B. (1998) The Quality of Family Planning Services for Breastfeeding Women in Senegal. International Family Planning Perspectives, 24, 188-190. 
[8] High Authority for Health (2013) Contraception in Postpartum Women. The Midwife Review, 12, 186-189.

[9] Mahmood, S.E., Srivastava, A., Shrotriya, V.P., Shaifali, I. and Mishra, P. (2011) Postpartum Contraceptive Use in Rural Bareilly. Indian Journal of Community Health, 23, 56-57.

[10] Genton, E. (2015) Review of the Information Received by Women on Postpartum Contraception during Their Stay in Childbirth. Final Thesis, Joseph Fourier University, Saint Martindale, France.

[11] Graesslin, O., Dedegker, F., Grolier, F., et al. (2004) Patch, Ring, Implants. New Hormonal Contraceptives. Update in Obstetric Gynecology. National College of French Gynecologists and Obstetricians, Vigot, 209-232.

[12] Bonacho, I., Pita, S. and Gomez-Besteiro, M.I. (1999) Eight Years with the Same IUD. Contraception, 59, 233-236. https://doi.org/10.1016/S0010-7824(99)00022-0

[13] Robin, G., Massart, P., Graizeau, F. and Du Masgenet, B.G. (2008) La Contraception du Post-Partum: État des Connaissances Postpartum Birth Control: State-of-the-Art. Gynécologie Obstétrique \& Fertilité, 36, 603-615.

https://doi.org/10.1016/j.gyobfe.2008.02.023 